\title{
TRIBUNAIS DE CONTAS SÃO OS GUARDIÕES DO DINHEIRO PÚBLICO
}

Coluna publicada em 14.1.2014: <http://www.conjur.com.br/2014-jan-14/ contas-vista-tribunais-contas-sao-guardioes-dinheiro-publico $>$

Em 17 de janeiro de 2014 comemora-se o Dia dos Tribunais de Contas. Muito poucos sabem disso. Não é para menos. Ainda hoje muitos não sabem o que são e o que fazem os Tribunais de Contas. Uma grande injustiça com estes órgãos tão importantes e que prestam um serviço da mais alta relevância para o país.

Seguramente o órgão público que mais intensa e diretamente trata com questôes de Direito Financeiro, nada mais justo do que começar este ano prestando-lhes uma merecida homenagem nesta coluna, que há mais de um ano trata deste tema e raras referências fez a eles.

Os Tribunais de Contas surgiram no Brasil pelo Decreto 966-A, de 7 de novembro de 1890, que, por iniciativa do então ministro da Fazenda, o renomado jurista Rui Barbosa, signatário da exposição de motivos, criou o Tribunal de Contas da União. Em 1891 foi contemplado na primeira Constituição da República, no artigo 89, já lhes assegurando independência funcional ("É instituído um Tribunal de Contas para liquidar as contas da receita e despesa e verificar a sua legalidade, antes de serem submetidas ao Congresso. Os membros desse Tribunal serão nomeados pelo Presidente da República, com aprovação do Senado, e somente perderão os seus lugares por sentença"). Sua instalação, no entanto, só veio a ocorrer no dia 17 de janeiro de 1893 (daí a escolha da data comemorativa), por empenho de Serzedello Correa, ministro da Fazenda do governo Floriano Peixoto, e que hoje empresta seu nome ao instituto de estudos e aperfeiçoamento funcional instalado no TCU e vem prestando valiosos serviços no aprimoramento do direito financeiro, administrativo e gestão pública.

Previsto no artigo 71 da Constituição Federal, o Tribunal de Contas da União tem a função de auxiliar o Congresso Nacional na missão de exercer o controle 
externo da administração pública federal, realizando a fiscalização contábil, financeira, orçamentária, operacional e patrimonial quanto à legalidade, legitimidade, economicidade, aplicação de subvenções e renúncia de receitas.

Em nosso sistema federativo, o controle externo dos demais entes federados é sempre exercido pelo respectivo Poder Legislativo, auxiliado pelo Tribunal de Contas competente, conforme dispõe a legislação específica. Cada ente da federação dispõe de um Tribunal de Contas responsável por exercer as funções que lhe são constitucionalmente atribuídas, em forma que pode variar de um para outro. Em regra, há um Tribunal de Contas do estado que auxilia a Assembleia Legislativa e as Câmaras Municipais no exercício dessa função de controle externo. Outros dispõem de dois tribunais de contas estaduais; o Tribunal de Contas do Estado, para a administração pública estadual, e o Tribunal (ou Conselho) de Contas dos Municípios, para as administrações públicas municipais. A atual Constituição Federal vedou a criação de tribunais de contas municipais (art. 31, $\$ 4^{\circ}$ ), mas permaneceram os já instalados, nos municípios de São Paulo e Rio de Janeiro.

Auxiliam o Poder Legislativo, mas a ele não se subordinam, não havendo qualquer relação de hierarquia, sendo dotados de autonomia institucional para cumprirem essa e outras funções determinadas diretamente pela Constituição (STF, ADI 4.190).

O Brasil adota o sistema de controle externo "continental-europeu", com um órgão colegiado responsável pelo controle externo das contas públicas, diferentemente dos países de origem britânica, que preferem o modelo de controladorias, como se vê no Reino Unido (National Audit Office - NAO), Estados Unidos (Government Accountability Office - GAO) e Austrália (Australian National Audit Office - ANAO), para citar alguns exemplos.

Daí nossos Tribunais de Contas, que são compostos por nove ministros (Tribunal de Contas da União), sete ou cinco conselheiros no caso dos tribunais de contas estaduais ou municipais, respectivamente, devendo estes últimos seguir o modelo federal, por simetria. Escolhidos entre brasileiros que satisfazem os requisitos do artigo $73, \$ 1^{\circ}$, da Constituição Federal, destacando-se a idoneidade moral e reputação ilibada, bem como os notórios conhecimentos, os ministros e conselheiros gozam das garantias e prerrogativas que lhes permitem agir com independência, necessária para que possam fiscalizar com imparcialidade as contas dos governantes e gestores que administram os recursos públicos. Em muitos entes da federação, ainda se vê a prática de adotar critérios predominantemente políticos na escolha desses cargos de cúpula, o que, evidentemente, não é o melhor caminho. Não impediu que tivéssemos, e ainda tenhamos, grandes nomes, mas seguramente 
não é o ideal, e a tendência é de que cada vez mais sejam consideradas as qualidades técnicas na escolha, que cabe aos poderes Legislativo e Executivo.

Com quadros formados por servidores concursados, entre os quais os das duas carreiras que o integram e têm assento no colegiado - a de auditores e a do Ministério Público de Contas, a competência profissional dos recursos humanos dos Tribunais de Contas tem se destacado, e eles são responsáveis por muito do que se melhorou em qualidade do gasto público nos últimos anos.

A função que lhes é confiada pelo artigo 71 e outros da Constituição é, como qualquer pessoa pode notar, tarefa ampla, complexa, que exige muito trabalho e competência. E no exercício de sua missão, os Tribunais de Contas têm sido responsáveis por grandes avanços no aprimoramento do Direito Financeiro, desenvolvendo estudos e técnicas que colaboram para o melhor uso do dinheiro público.

Muitas dessas funções merecem destaque, e a referência a apenas parte delas certamente importará em omissões, mas muitas oportunidades ainda haverá para serem mencionadas.

A fiscalização da renúncia de receitas, cuja referência na Constituição é expressa, tem sido objeto de especial atenção, com análises e relatórios detalhados e específicos. ${ }^{1}$ Afinal, como já se reconhece há muito, recursos dos quais o governo abre mão por benefícios fiscais diversos equiparam-se às despesas, tanto que a doutrina os denomina de "gasto tributário". ${ }^{2}$ São recursos públicos, e, portanto devem merecer atenção redobrada, pois são menos transparentes e mais difíceis de serem fiscalizados. O mesmo se diga em relação a benefícios creditícios governamentais, que estão a exigir cada vez mais atenção.

Foi-se o tempo em que os Tribunais de Contas se ocupavam apenas da fiscalização de conformidade, sob o aspecto da legalidade, concentrando-se nas formalidades da despesa pública. Muito se avançou, e continua se avançando, na fiscalização da qualidade do gasto público, levando-se em consideração a eficácia, efetividade, eficiência e economicidade no uso dos recursos públicos, pois o que realmente importa são os resultados e benefícios alcançados, e não o cego respeito a uma burocracia, não raro, obsoleta.

Relatórios sobre as contas do governo mais abrangentes, com avaliação das macrofinanças governamentais e das políticas públicas que vêm sendo desenvolvidas, apontando-se falhas e sugerindo soluções e aperfeiçoamentos, mostram-se

TCU, Plenário, AC 74/2010, Processo TC 015.052/2009-7, sessão 14 de abril de 2010.

2 Ou tax expenditure, para usar a expressão consagrada por Stanley Surrey em seus pioneiros trabalhos sobre o tema. 
cada vez mais frequentes, tornando os Tribunais de Contas órgãos que atuam preventiva e propositivamente, e não apenas na fiscalização a posteriori, quando o dinheiro já foi gasto e só resta a punição dos responsáveis se houver mau uso.

Muito dinheiro público é economizado a partir de recomendações e determinações dos Tribunais de Contas em razão de sua atividade de fiscalização das políticas públicas, como ocorreu recentemente na área da educação, após avaliação dos programas do Fies e Prouni pelo TCU, em que se estima terem sido economizados mais de R 300 milhões em $2013 .{ }^{3} \mathrm{Ou}$, de outro lado, ajudando a melhorar a arrecadação, como se vê nas sugestóes para incrementar a cobrança da dívida ativa pela via extrajudicial, o que colabora ainda para desafogar o Poder Judiciário que sofre com o excesso de execuções fiscais, prejudicando a prestação jurisdicional em outros setores mais relevantes. ${ }^{4}$

Mostra-se também intensa a fiscalização de editais e contratos da administração pública, bem como a execução de obras públicas, sendo frequentes as e suspensões de editais e constatações de irregularidades graves que levam ao cancelamento de repasses de recursos, impedindo a continuidade no desperdício do dinheiro que é de todos nós.

Os Tribunais de Contas dispóem de instrumentos eficientes para evitar o mau uso do dinheiro público, como os alertas a que se refere o artigo $59, \S 1^{\circ}$, V, da Lei de Responsabilidade Fiscal, com os quais informam os gestores sobre ultrapassagem de limites de gastos e endividamento, indícios de irregularidades e outros que possam comprometer a boa gestão das contas públicas. Atualmente tem sido intensificado seu uso, mostrando essa importante ação de natureza preventiva, seguramente a melhor forma de evitar a má gestão das contas públicas.

Punir nem sempre é o melhor caminho para melhorar as coisas, mas, muitas vezes, é necessário, e os Tribunais de Contas têm muitos instrumentos para isso. Entre as principais está a multa, que, embora pouco conhecida do grande público, é largamente aplicada. Também as condenaçōes ao ressarcimento do dano ao erário têm se mostrado frequentes e com importante efeito pedagógico, além de serem responsáveis pela recuperação de boa parte dos prejuízos causados ao Estado. Políticos e gestores são punidos com frequência, evidentemente não gostam, e estejam certos de que disso resultam muitas das críticas que sofrem os Tribunais de Contas.

Muitas linhas, parágrafos e páginas são necessários para enumerar tudo que os Tribunais de Contas já fazem, podem e devem fazer para cuidar do nosso

\footnotetext{
TCU, AC 2.873/2013, Processo TC 000.997/2013-7, sessão 23 de outubro de 2013.

4 TCE São Paulo, Pleno, Consulta, Proc. TC 041852/026/10, sessão 8 de fevereiro de 2012.
} 
dinheiro, e este espaço evidentemente não comporta. Ainda há muito a fazer, e todos podem ajudar, pois, da mesma forma que o controle interno ao qual já me referi anteriormente, ${ }^{5}$ os Tribunais de Contas dispõem de ouvidorias para receber denúncias de irregularidades ou ilegalidades (CF, art. 74, $\$ 2^{\circ}$ ). E parabéns aos Tribunais de Contas pelo seu dia!

5 Controle interno mostra sua força no combate à corrupção, nesta edição, p. 313-316. 
